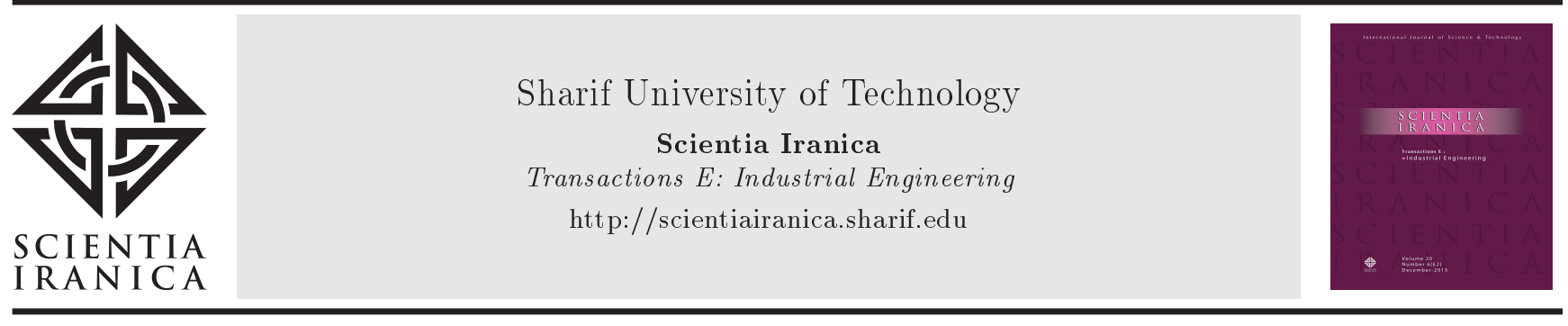

\title{
Simulation-based optimization using DEA and DOE in production systems
}

\author{
N. Monazzam, A. Alinezhad*, and M.A. Adibi \\ Faculty of Industrial and Mechanical Engineering, Qazvin Branch, Islamic Azad University, Qazvin, Iran.
}

Received 23 February 2020; received in revised form 5 October 2020; accepted 18 January 2021

\section{KEYWORDS}

Production system; Simulation;

DOE;

DEA;

SWARA.

\begin{abstract}
Production System (PS) is the process of planning, organizing, directing, and controlling the tactical and strategic planning of different components of a company in order to transform inputs into finished products, which must be effectively managed. Important parts of a PS that always face major challenges in manufacturing include production strategy, resource allocation, logistics, and production planning. Because of the importance of examining various PS components and evaluating their performance in key indicators of organization, it is necessary to evaluate the impact of any changes in these elements on the system prior to its creation. In this regard, the present study aims to increase the efficiency and determine the useful methods to evaluate and optimize the performance of different PS parts. To this end, an integrated Discrete-Event Simulation (DES), Design Of Experiments (DOE), Data Envelopment Analysis (DEA), and MultiAttribute Decision Making (MADM) models were implemented to analyze and optimize the real PS process. In the case study of the automobile manufacturing industry in Iran, accurate analysis was applied to the proposed approach and its different aspects were considered, as well. The results indicate that the proposed approach is a practical way for evaluating and optimizing the performance of different PS parts, compared to previous models, and helps manufacturing companies make efficient decisions regarding increased productivity and fewer essential problems.
\end{abstract}

(C) 2022 Sharif University of Technology. All rights reserved.

\section{Introduction}

Production System (PS) is the process of planning, organizing, directing, and controlling production activities in an organization to transform inputs into finished products in line with the strategic objectives of an organization. It is a function that is responsible

\footnotetext{
*. Corresponding author. Tel.: +9828 33665275 ;

Fax: +982833665279

E-mail addresses: nafise.monazam7@yahoo.com (N.

Monazzam); alalinezhad@gmail.com (A. Alinezhad);

maadibi.qiau@gmail.com (M.A.Adibi)
}

doi: $10.24200 /$ sci.2021.55499.4253 for tactical and strategic planning of the components of a company, consisting of many elements that must be effectively managed. Essential parts of a PS that always face significant challenges in manufacturing systems include production strategies, resource allocation, logistics, production planning, and flow of products. Each of these departments independently performs tasks in the system and they contribute to the shortand long-term goals of the organization. This is the reason why in industrial businesses, optimizing the performance of a PS in different manufacturing sectors is one of the most critical issues today in order to achieve the goals of the organization. Further, PS with the aim of planning, organizing, directing, and 
controlling the activities of the production process plays a substantial role in promoting productivity and controlling the factors that influence the organization. Moreover, the systematic PS leads to an efficient and optimal production chain as well as increased return of capital by promoting the quality of intensely competitive global markets of manufacturing industries and responding quickly and accurately to the needs of customers. It also provides sufficient strength to overcome the biggest manufacturing challenge, i.e., the growing complexity of manufacturing systems, for dealing with the challenges imposed by variability, uncertainty, and randomness [1]. Furthermore, an increase in PS efficiency requires:

(a) Operational and detailed planning on different parts of PS concerning the strategic objectives of the organization and production flow planning while minimizing the costs;

(b) Rational and continuous utilization of the workforce, materials, and processing equipment.

The performance optimization for PS using useful methods can help each manufacturer solve the problems, that is, reducing transportation costs, optimizing production lines, ensuring the continuity of processes from supply to sales, and finally, evading shocking variations in the PS. Therefore, the performance evaluation for PS is considered an important means to achieve the intended goals.

PS performance evaluation taking into account all its essential parts yields maximum PS efficiency. Previous studies have modeled and simulated different processes of a PS with validated results over the past years. For instance, Abdulaziz et al. proposed a combined model of Discrete-Event Simulation (DES) with System Dynamics (SD) and mainly aimed to assess the green logistics practices in the automotive industry [2]. They did not take into account the effects of the proposed model on the PS and the flow of products, thus affecting the rate of production and profitability of products. Dumetz et al. presented a simulation framework for evaluating and comparing different production planning as well as order management strategies [3]. Heidarzadeh et al. developed a supply chain strategy in an automotive industry [4]. Vieira et al. considered simulation analysis for complex production scheduling problems with the stochastic behavior [5], and Müller et al. proposed a method to set up a system by simulating online production planning systems [6]. Production planning done in isolation irrespective of its application to different parts of a system and its impact on other components cannot provide a clear picture of the production process and system performance. Zahraee et al. suggested using an integrated computer simulation, a response surface methodology, and Design Of Experiments (DOE) model in a continuous production line, given the role of essential factors in the functionality of the paint manufacturing system [7]. Caterino et al. implemented DES to verify the improvement of existing production lines or the design solution adopted for a new line to optimize the process [8]. Moreover, Pawlewski employed simulation modeling for a PS with the aim of the flowing of materials [9]. Motlagh et al. further applied the simulation optimization methodology to improve the performance of production lines. This increases the productivity and efficiency of the entire production system [10]. Further, Vaisi and Ebrahimi introduced a hybrid computer simulation, Data Envelopment Analysis Goal Programming (DEAGP), and DOE model in the manufacturing of automobile spare parts. They aimed to extend a simulation model based on a real system in order to improve the PS performance [11].

In manufacturing industries, increasing the efficiency of production halls does not necessarily increase the overall system productivity and improve the strategic goal indices. Therefore, in addition to improving the performance of the PS, it is necessary to consider external factors associated with the production hall such as logistics and the effects of system changes on critical indicators such as production rate of the whole system and benefits of the organization. Therefore, as discussed in the preceding paragraph, considering different PS components in a production process is of great importance in enhancing the efficiency and productivity. Besides, simultaneous effects of different components on each other and the consequential impact on the strategic indicators of the whole system have not been assumed in any study so far. Consequently, this research made an attempt to fill this gap. Although this integration is necessary for decisionmaking, the methods used in this evaluation are also of particular importance.

The current study uses a combination of DES, DOE, Multi-Attribute Decision Making (MADM), and Data Envelopment Analysis (DEA) approaches. First, the DES method is used to model the production processes by considering different parts of PS. Then, according to the essential indices of the organization, the DOE method was applied to generate the scenarios. Afterwards, using MADM, the weight of indicators was determined and finally, through the application of the DEA method, the performance of scenarios was evaluated and the optimal one was obtained.

Simulation modeling is a useful method for all managers, researchers, and practitioners to analyze the dynamic systems without interrupting their operations [12]. In real complex systems, computer simulation can be used to mimic the behavior of the system over time and to access data similar to the real system. Furthermore, the DES method is beneficial 
at the operational level of projects. The simulation of operational processes sheds light on the project condition by considering different discrete variables such as process duration, resource utilization, cycle time, throughputs, and entity arrival rate [13]. Kaylani and Atieh proposed a simulation approach to enhance production scheduling procedures. Their results for potential changes may not be valid unless the simulation model is optimized using optimization tools [14]. Kumar et al. proposed a model in Toyota production system regarding productivity enhancement and cycle time reduction [15]. Gyulai et al. applied a simulation approach based on production planning in the automotive industry. The model did not consider a proper method for designing and analyzing the scenarios of the simulation approach [16]. In largescale simulation, a sophisticated computer experiment frequently requires permutation among hundreds or even thousands of input variables and takes a long time to run each excursion [17]. Thus, PS performance evaluation can be utilized through Optimization Via Simulation (OVS), which is based on DES principles and considered as one of the most essential techniques.

The DEA method is an effective non-parametric evaluation method for measuring the relative efficiency of a set of Decision-Making Units (DMUs) that use multiple inputs to produce multiple outputs [18]. Also, it is a nonparametric approach that requires no assumption about the functional form of production $[19,20]$. Thus, DEA could be beneficial to every industry or organization in which a logically homogeneous set of DMUs uses a similar set of inputs in order to produce a certain range of outputs $[21,22]$. Further, the impact of experts' preferences in DEA models makes the results more precise. Therefore, MADM method incorporating the impact of the experts' preferences can be considered for weighting the input and output indicators of the DEA model. Park et al. used the hybrid stochastic DES and DEA model for vendor selection [23]. In another study, Ebrahiminejad et al. proposed an integrated DEA and simulation approach to group consensus ranking [24]. Moreover, Azadeh et al. applied integrated simulation and stochastic DEA to the facility layout design problem [25]. In these studies, the weight of DEA indicators was not determined and simulation scenarios were designed based on experts' opinions, which may not be precise enough.

The DOE method is utilized for designing and evaluating simulation modeling scenarios. Furthermore, the application of experimental designs and simulation for improving productivity play a leading role in the success of projects that are time- and budget-bound. Thus, the result will be more credible and reliable since all possible combinations of factors are evaluated using the methods mentioned earlier [7]. Marlin and Sohn presented a hybrid analytical process that combined simulation, DOE, and DEA in the Afghan educational system. In this study, the importance of DEA indicators remained undetermined [17].

The DES, DOE, and DEA methods are considered to be suitable methods for evaluating the behavior of a system [12]. Previous evaluations in this field indicate that the simulation results serve as an input to DOE or DEA techniques for analyzing a system. With DEA at hand, scenario design is not precisely possible and scenarios are often designed based on experts' opinions and empirical experiments. Also, in DOE, after performing simulation experiments, it is not possible to carefully examine the efficient scenarios and improve their performance close to efficiency based on the organization status. Moreover, MADM approaches can help the DEA keep the calculations more accurate. Thus, upon combining these four techniques, this research attempts to propose a comprehensive and practical approach that can be used in any industrial company.

The current study investigates a real sample involving the complexity and variety of products in Iran's automobile manufacturing industry for six months and performs the accurate analysis of the model accordingly. Compared to the other recent studies, the present study attempts to fill the gap in the literature through the optimization of different PS parts such as logistic, production strategies, production planning, and productivity of production halls, thus presenting a novel approach. In this regard, we identified bottlenecks, the components that demanded change the most, key organizational indicators, and different parts of the real-world PS process simulated. Then, the impacts of different parts on each other were evaluated. The model outputs were used as the raw data of the $2^{k}$ factorial design of DOE, and the designed scenarios were evaluated by the Ratio Efficiency Dominance (RED) and the Step-wise Weight Assessment Ratio Analysis (SWARA) techniques. Finally, this study aims to help managers manage their enterprise efficiently and deal with the bottleneck problems related to the Iran Khodro Industrial Plant, which, to the best of our knowledge, have never been addressed before.

The remaining parts of the present study are organized as follows. Section 2 describes the proposed approach. Besides, Section 3 provides a case study to demonstrate how to use the framework. Section 4 discusses the effects of the combined methods in the proposed approach. Section 5 summarizes the concluding remarks.

\section{Proposed approach}

It is of significance to examine the various components of PS and evaluate their performance in key indicators of the organization. Therefore, it is necessary to 


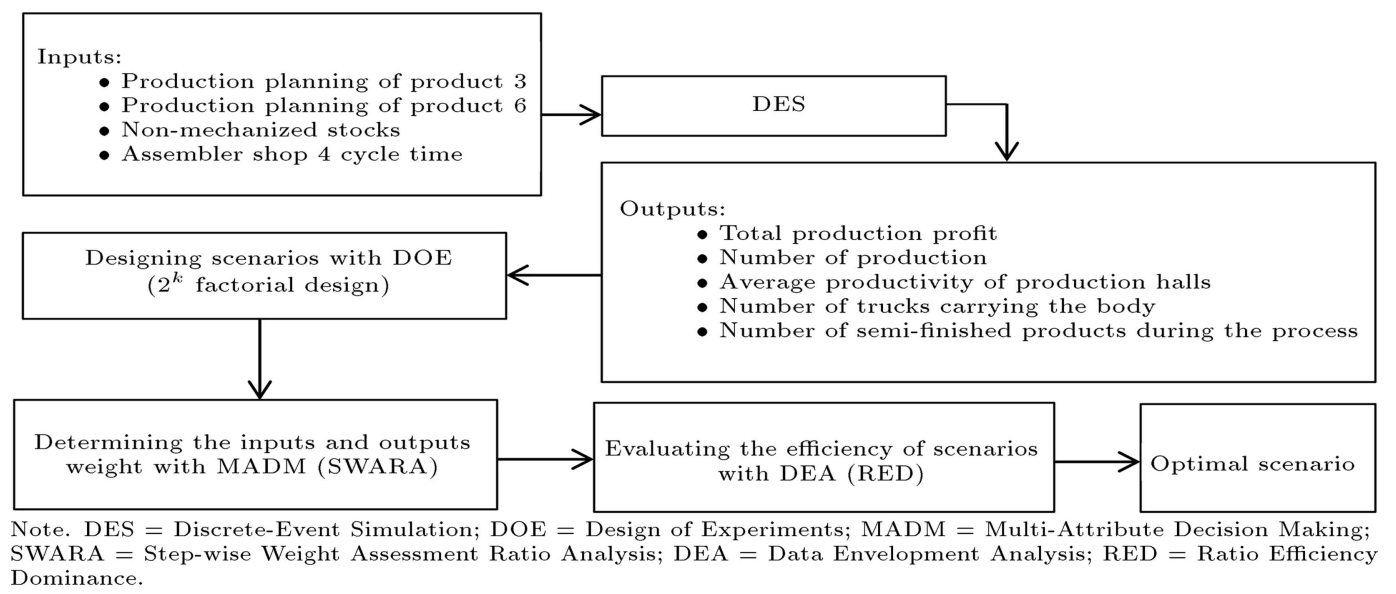

Figure 1. Schematic view of the proposed approach.

evaluate the impact of any changes on the system performance before its creation. In this regard, the present study aimed to optimize the performance of different parts of PS in a system in uncertain conditions via simulation. To this end, the current state of the manufacturing system was modeled first using a DES, and the decisive factors and the decision variables were characterized accordingly. The main reason for choosing this method is that OVS is mostly based on discrete event simulation principles and is crucial to both the application of this technique and recognition of the system by analysts. In other words, one random event is sampled at least in the actual model; the state of the system varies at discrete time intervals; and there are numerous decision variables.

In the real world, there is no clear mathematical relationship between controllable decision variables and objective (response) variables. The second step after modeling the system via simulation is the use of Metamodel based Methods, meaning that they seek to establish a clear mathematical relationship between response variables and controllable decision variables; hence, upon designing an experiment and determining possible levels for each decision variable, structured data are collected and for each scenario, simulation software model is run in determined numbers. Consequently, the number of decision variables and response variables is recorded each time. In this regard, the scenarios are designed utilizing the DOE model, followed by determining the optimal value of decision variables using DES.

The next step to provide a precise analysis regarding each decision variable and response variable is to determine the weight and priority; to this end, MADM methods are used which represent a common set of weights that express the preferences of decision-makers. The MADM method used in this study is SWARA, which is a rational technique for dispute resolution and allows the assessment of differences in attribute significance that characterizes the decision alternatives. The main feature of SWARA method is the possibility to estimate the significance ratio of the attributes in the process of their weight determination based on experts or interest groups' opinion, and experts play an important role in calculating the weight and evaluating the indicators. Furthermore, this method is compensatory in nature and its corresponding indicators are independent. At the same time, in this method, qualitative indicators should be converted into quantitative ones [26].

Afterwards, the performance of the scenarios should be evaluated comparatively. DEA is a nonparametric method of calculating efficiency and separating efficient scenarios from inefficient ones as well as identifying the causes behind the inefficiency of such scenarios. In this regard, the efficiency of the scenarios as a DMU is determined using the RED model. The efficiency score which is based on the initial definition of efficiency dominance and ratio efficiency is calculated for each DMU using the input and output of all the DMUs. Instead of using LP to optimize the efficiency of a DMU with respect to other DMUs, in this method, the efficiency score of a DMU is compared with those of other DMUs based on the weight value calculated by normalization function in order to determine its ranking. The RED method addressed the issues of computation time and accuracy in efficiency evaluation of DMUs specifically for large datasets [27].

The proposed approach keeps the calculation more precise because without a combination of DOE and DEA approaches, we may not be able to design scenarios and analyze their efficiency at the same time. These two methods complement each other and make the results more realistic and accurate. Furthermore, DEA cannot take into account expert opinions and by means of SWARA, we surely have access to a superior analysis. Figure 1 illustrates the schematic view of the proposed approach. 


\subsection{Discrete-Event Simulation (DES)}

In recent years, the technological advancements in computer simulation as an appropriate approach have guaranteed the feasibility and effectiveness of the designed process plan in a variety of engineering issues [28]. The direct use of simulation for real-time decision-making in the manufacturing process is common before launching a new production [29]. A DES model enables the analysis of the dynamic of the stochastic system. Also, the above model is used to verify the functioning of a new element in the process and allow for evaluating both the operations and resources of the system and the mechanical efforts of a new device installed at a plant [30]. In the DES, the state of the system changes only during specific time instants, which are defined as the events. Further, simulation can be considered in the form of a list of events that are ordered by a timestamp where an event can edit the status of the system, add new future events, or remove the already scheduled events [31,32]. In the current study, the Enterprise Dynamics (ED) is used, which is a DES simulation software platform developed by INCONTROL Simulation Solutions. The following seven steps provide the best practice in simulation in order to achieve better results with respect to the expected goals [30]:

Step 1. Defining the goals: In the first step, the objectives should be determined since they suggest what areas to emphasize in the process. In the present study, the objectives were characterized by experts of the manufacturing system;

Step 2. Providing a conceptual description: Conceptual definition is a crucial step for developing a simulation model. In this study, a conceptual description was provided for the manufacturing factory by observing its production lines, production flows, logistic paths, and warehouses;

Step 3. Collecting the required data: In this step, analyzing the actual system in order to evaluate what information is relevant for building the model is essential. The required data were collected by designing the production processes and production flows of the manufacturing plant such as the number of the conveyors, queues, logistic paths, number of truck loaders, cycle times, travel times between the sequential halls, conveyer speeds, etc.;

Step 4. Building the simulation model: In this step, ED simulation software was used for building the current state of the manufacturing system;

Step 5. Verifying and validating the model: Before collecting the results, investigating the verification and validation of the simulation model is necessary. In the present study, the verification of the model was determined using ED software abilities and the validation was performed utilizing the paired t-test;

Step 6. Simulating: At this phase, a simulation experiment is defined and run within an acceptable time horizon. Finally, a time horizon for this model was determined to be 100 times in 24 hours;

Step 7. Analyzing the results: In the final step, the results should be critically analyzed to decide whether to represent valid information for the goals. A negative answer could force the simulation process to restart from Step 2.

\subsection{Design Of Experiment (DOE)}

Factorial designs widely applied to experiments involve several factors and studying the joint effect of the factors on a response is a matter of importance. $K$ factors, each at only two levels, are considered as the most important and special cases, as presented in the current study. The process of the $2^{k}$ factorial design is summarized in the following steps [33]:

Step 1. Choosing effective factor, levels, and response variables: The response variable of experiments was determined in this step. Then, effective factors and their levels, which can affect the substantiation of outputs, were generated with respect to decision experts;

Step 2. Forming the initial model: The $2^{k}$ factorial design with respect to effective factors and response variables was applied in Step 2. In the present study, the $2^{4}$ factorial design was used based on four factors;

Step 3. Performing the experiments: In this step, the simulation model was developed and the results were extracted for each experiment (scenario);

Step 4. Interpreting the results: Finally, the response variables were interpreted after developing the simulation model for each experiment.

\subsection{Step-wise Weight Assessment Ratio Analysis ( $S W A R A)$}

Decision-making approaches act as a boon for the person seeking to reach some conclusions by keeping all the favorable and unfavorable conditions in their mind [34,35]. Multi-Criteria Decision-Making (MCDM) paradigm is considered as the most famous wing of decision-making theory. Each MCDM technique has its advantages and disadvantages [36] and can be classified into two categories. Based on the number of alternatives under consideration, differences can cater between MADM and Multi-Objective DecisionMaking (MODM) [37].

The SWARA method, as one of the new MADM methods, was developed by Kersuliene, Zavadskas, and Turskis [26] in 2010. In the present study, the compelling factor (input) and response variable (output) weights were calculated using the SWARA method. 
The input of SWARA, as a relative importance value $\left(S_{j}\right)$, is provided by decision-makers, and this technique involves five steps [26]:

Step 1. Initially, indicators are prioritized according to the importance given by decision-makers.

Step 2. Beginning with the second attribute, the relative importance indicates the $j$ th attribute in relation to the previous attribute $(j-1)$ and this process is performed for each attribute. This ratio is called "average relative importance" $\left(S_{j}\right)$.

Step 3. The coefficient $K_{j}$ is calculated using Eq. (1):

$$
K_{j}=\left\{\begin{array}{ll}
1 & j=1 \\
S_{j}+1 & j>1
\end{array} \quad j=1, \cdots, n,\right.
$$

where $j$ is an attribute number and $S_{j}$ is the comparative importance of average value.

Step 4. The initial weight is derived from Eq. (2):

$$
q_{j}=\left\{\begin{array}{ll}
1 & j=1 \\
\frac{q_{j-1}}{K_{j}} & j>1
\end{array} \quad j=1, \cdots, n,\right.
$$

where $j$ is an attribute number, $K_{j}$ a coefficient of each attribute, and $q_{j}$ a recalculated weight.

Step 5. The weights of attributes are determined through Eq. (3):

$$
W_{j}=\frac{q_{j}}{\sum_{j=1}^{n} q_{j}} ; \quad j=1, \cdots, n,
$$

where $q_{j}$ is a recalculated weight and $W_{j}$ is the weight of each attribute.

\subsection{Ratio Efficiency Dominance (RED)}

DEA is a methodology based upon an interesting application of linear programming. It has been successfully employed for assessing the relative performances of a set of firms, usually called DMUs, which use a variety of identical inputs to produce different identical outputs [38]. The Charnes, Cooper, Rhodes (CCR) model as the most popular DEA model was introduced first by Charnes et al. [22] in 1978. The idea is to define the efficiency measure by assigning to each unit the most favorable weight as long as the efficiency scores of all DMUs calculated from the same set of weights do not exceed one [39]. Let $X_{i j}, i=1, \cdots, m$ and $Y_{r j}, r=1, \cdots, s$ denote the $i$ th input and $r$ th output, respectively, of the $j$ th DMU, $j=1, \cdots, n$. The relative efficiency of DMU $k$ under the assumption of Constant Returns to Scale (CRS) is formulated via the following DEA model [39]:

$$
E_{k}=\max \sum_{r=1}^{s} u_{r} Y_{r k}
$$

s.t.:

$$
\begin{aligned}
& \sum_{i=1}^{m} v_{i} X_{i k}=1 \\
& \sum_{r=1}^{s} u_{r} Y_{r j}-\sum_{i=1}^{m} v_{i} X_{i j} \leq 0, \quad j=1,2,3, \cdots, n \\
& u_{r}, v_{i} \geq \varepsilon, \quad r=1, \cdots, s, \quad i=1, \cdots, m
\end{aligned}
$$

where $E_{k}$ is the efficiency of DMU $k, v_{i}$ and $u_{r}$ are the virtual multipliers associated with the $i$ th input and $r$ th output, respectively, and $\varepsilon$ is a small non-Archimedean number. This model is commonly denoted by the ratio-form DEA model because the constraint $\sum_{r=1}^{s} u_{r} Y_{r j}-\sum_{i=1}^{m} v_{i} X_{i j} \leq 0$ has a ratio form of $\sum_{r=1}^{s} u_{r} Y_{r j} / \sum_{i=1}^{m} v_{i} X_{i j} \leq 1$, which is just efficiency of DMU $k$ for $j=k$ [39].

In the current study, the RED model is utilized to compute the efficiency of DMUs (scenarios). Farahmand and Desa introduced this model in 2017. The speed of computing is highly essential due to the considerable amount of data and the number of DMUs. Furthermore, the time duration for computation was obtained for dual and primal simplex around 36 and $136 \mathrm{~h}$ for 100,000 DMUs, respectively. Also, this model can help evaluate the efficiency of DMUs in small, large, and substantial problems within a limited time span. The RED model includes seven steps [27]:

Step 1. Suppose $D M U_{j}=\left(X_{1}, X_{2}, \cdots, X_{m}, Y_{1}, Y_{2}\right.$, $\left.\cdots, Y_{s}\right)$ where $X_{j}=\left(x_{1 j}, x_{2 j}, \cdots, x_{m j}\right)$ and $Y_{j}=$ $\left(y_{1 j}, y_{2 j}, \cdots, y_{s j}\right)$ are input consumption and output production vectors, respectively, and $x_{i j}>0, y_{i j}>0$, $j \in\{1,2, \cdots, n\}$.

Step 2. If $x_{i p}=0$, then $x_{i p}=\min _{j \in p}\left\{x_{i j}\right\}-\varepsilon$, where $p \epsilon\{1,2, \cdots, n\}, \varepsilon=\frac{1}{n} \max _{j}\left\{x_{i j}\right\}$, and $j \in$ $\{1,2, \cdots, n\}$.

Step 3. The weighted normalized values of inputs and outputs are determined using Eqs. (8) and (9):

$$
\begin{aligned}
\omega_{i j} & =\mu_{i j} \cdot w_{i j}, \\
i & =1, \cdots, m, \quad r=1, \cdots, s, \quad j=1, \cdots, n, \\
\omega_{r j} & =\mu_{r j} \cdot w_{r j}^{\prime}, \\
i & =1, \cdots, m, \quad r=1, \cdots, s, \quad j=1, \cdots, n,
\end{aligned}
$$

where $i=1, \cdots, m, r=1, \cdots, s$, and $j=1, \cdots, n$ are inputs, output, and DMUs, respectively. $w_{i j}$ and $w_{r j}^{\prime}$ are calculated by the SWARA method based on the weight of the input and output indicators, respectively. Moreover, the normalized values of the inputs $\left(\mu_{i j}\right)$ and outputs $\left(\mu_{r j}\right)$ are computed using Eqs. (10) and (11) for each DMU: 


$$
\begin{aligned}
\mu_{i j} & =\frac{x_{i j}}{\max _{j}}\left\{x_{i j}\right\} ; \quad x_{i j}>0, \quad i=1, \cdots, m, \\
r & =1, \cdots, s, \quad j=1, \cdots, n, \\
\mu_{r j} & =\frac{y_{i j}}{\max _{j}}\left\{y_{r j}\right\} ; \quad y_{i j}>0, \quad i=1, \cdots, m \\
r & =1, \cdots, s, \quad j=1, \cdots, n,
\end{aligned}
$$

where $x_{i j}, i=1, \cdots, m$ and $y_{i j}, r=1, \cdots, s$ denote the $i$ th input and $r$ th output, respectively, of the $j$ th DMU and $j=1, \cdots, n$.

Step 4. The relative score of $D M U_{j}$ is computed through Eq. (12):

$$
\begin{aligned}
& S O D I_{j}^{*}=\sum_{i=1}^{m} \sum_{r=1}^{s} \frac{\omega_{r j}}{\omega_{i j}}, \\
& i=1, \cdots, m, \quad r=1, \cdots, s, \quad j=1, \cdots, n,
\end{aligned}
$$

where $S O D I_{j}^{*}$ is the relative score of $D M U_{j}, j=$ $1, \cdots, n . \omega_{i j}$ and $\omega_{r j}$ are weighted normalized values of inputs and outputs, respectively.

Step 5. The maximum relative score is obtained by Eq. (13):

$$
S O D I^{+}=\max _{j}\left(S O D I_{j}^{*}\right) ; \quad j=1, \cdots, n,
$$

where $S O D I^{+}$is the maximum relative score of the DMUs.

Step 6. The efficiency of $D M U_{j}$ is calculated through Eq. (14):

$$
S O D I_{j}^{-}=\frac{S O D I_{j}^{*}}{S O D I^{+}} ; \quad j=1, \cdots, n,
$$

where $S O D I_{j}^{-}$is the efficiency of $D M U_{j}, j=$ $1, \cdots, n$, which is obtained by dividing the relative score of $D M U_{j}\left(S O D I_{j}^{*}\right)$ and the maximum relative score of DMUs $\left(S O D I^{+}\right)$.

Step 7. Classify the efficiency level in descending order, rank the DMUs according to their scores, and analyze the results. The DMU with value 1 is determined as the most efficient one.

\section{Experiment}

\subsection{System description}

The producer of automobile products in Tehran, Iran is considered to be a practical case in association with Iran Khodro Company. Iran Khodro is one of the largest industrial plants in the Middle East. Besides, this company has eight body shops, three paint shops, and four assembler shops independently and produces eight different products. In addition to the significant logistics between the production halls, the state of supply, the capacity of production lines, product flow, etc. can provide various complexities and problems for the company in order to achieve its goals. The actual case of this study indicates the efficiency and effectiveness of the proposed approach. Figure 2 displays the existing condition of the company.

The manager of the plant would like to assure that their PS is efficient in the entire production process. In other words, the company would like to know what production scenarios are efficient if the current PS is inefficient. The experience learned from this study is expected to provide the overviews for future PS performance evaluation and optimization.

The following assumptions are considered in the proposed approach. By considering the stated assumption, DES, DOE, DEA, and MADM approaches are explained as well:

- The material flow is initiated from the body shops;

- The manufacturing system is continuous;

- The cycle times are determined based on the probability distribution and the nature of the manufacturing system;

- The loading and offloading of the parts, bodies, and the like by the insoles are limited;

- The production planning of each product is considered in the body shop halls;

- The body shop stock halls are called WBS (Without paint Body Stock) and the paint shop stock halls are called PBS (Painted Body Stock);

- Several painted body products are sent to five different sites, which are far from the central site.

\subsection{Data collection}

In this section, the optimization of PS is evaluated in the automobile manufacturing industry in Iran. The productive system produces eight different products totaling 2050 products daily. The structure of the real model under investigation is summarized using the conceptual model (Figure 2).

Based on production planning, the primary components enter the body shops and then, receive some services and become the iron bodies. Next, the bodies are transported to paint shops utilizing the conveyors or logistic paths and converted into painted bodies. Then, they move to the final circuit and enter the assembler shops. Finally, the products turn into a complete automobile.

Further, some painted bodies, as Semi-KnockedDown (SKD), are sent to several shops such as Assembler shop 5 (Fars), Assembler shop 6 (Kermanshah), Assembler shop 7 (Semnan), Assembler shop 8 (Khazar), and Assembler shop 9 (Tabriz) in different 


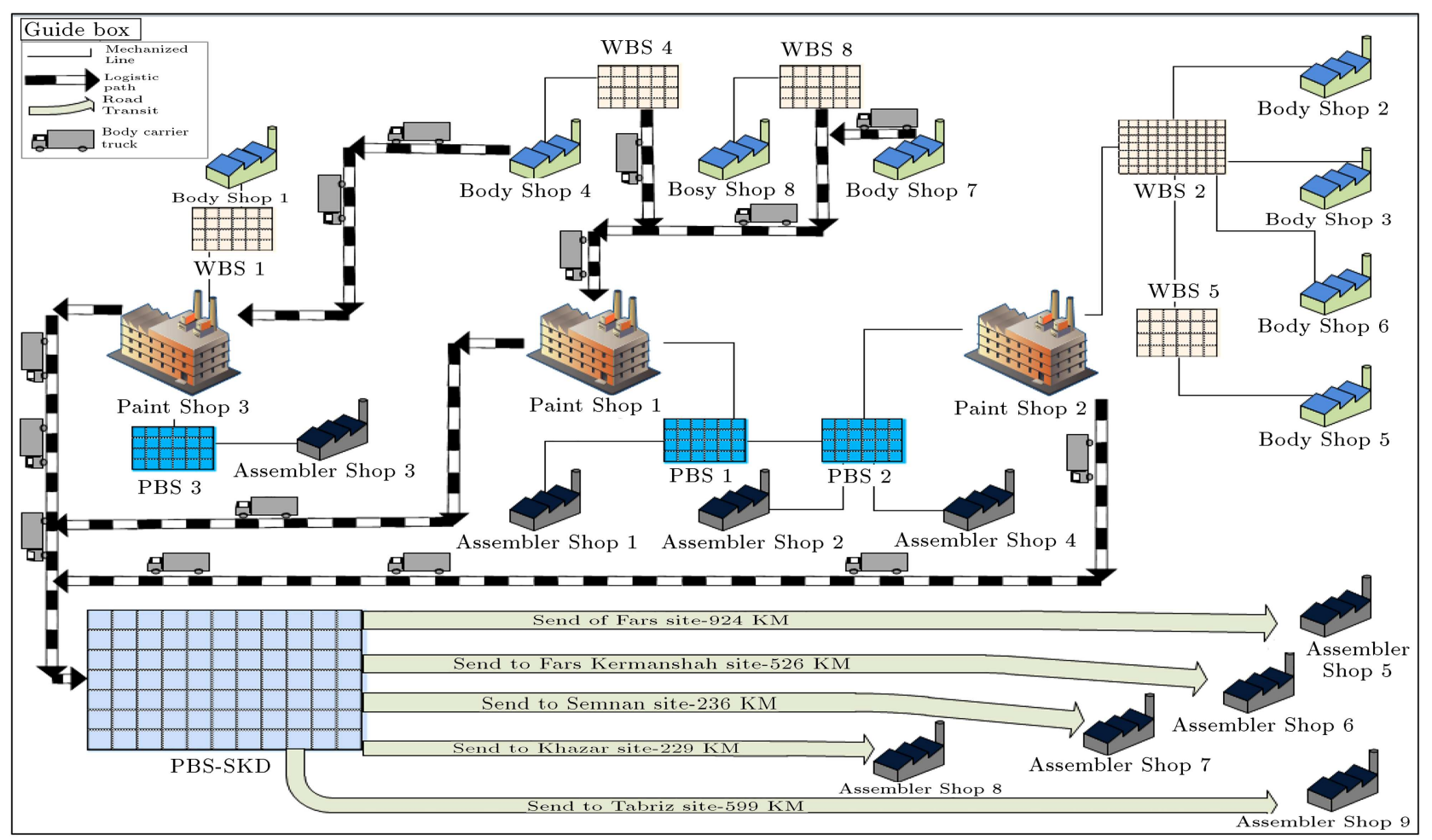

Note. WBS = Without paint Body Stock; PBS = Painted Body Stock; SKD = Semi-Knocked-Down

Figure 2. The existing condition of the company.

Table 1. The information of the production flow of each product.

\begin{tabular}{|c|c|c|c|c|c|c|c|c|c|c|c|c|c|c|c|c|c|c|c|c|}
\hline \multirow{2}{*}{ Product } & \multicolumn{8}{|c|}{ Body shop } & \multicolumn{3}{|c|}{ Paint shop } & \multicolumn{9}{|c|}{ Assembler shop } \\
\hline & 1 & 2 & 3 & 4 & 5 & 6 & 7 & 8 & 1 & 2 & 3 & 1 & 2 & 3 & 4 & 5 & 6 & 7 & 8 & 9 \\
\hline 1 & 1 & 0 & 0 & 0 & 0 & 0 & 0 & 0 & 0 & 0 & 1 & 0 & 0 & 1 & 0 & 0 & 0 & 0 & 0 & 0 \\
\hline 2 & 0 & 1 & 0 & 0 & 0 & 0 & 0 & 0 & 1 & 1 & 0 & 0 & 0 & 0 & 0 & 0 & 0 & 0 & 0 & 1 \\
\hline 3 & 0 & 0 & 1 & 0 & 0 & 0 & 0 & 0 & 1 & 1 & 0 & 0 & 1 & 0 & 0 & 0 & 0 & 0 & 0 & 0 \\
\hline 4 & 0 & 0 & 0 & 1 & 0 & 0 & 0 & 0 & 1 & 0 & 1 & 0 & 0 & 0 & 0 & 1 & 1 & 1 & 1 & 0 \\
\hline 5 & 0 & 0 & 0 & 0 & 1 & 0 & 0 & 0 & 0 & 1 & 0 & 0 & 0 & 0 & 1 & 0 & 0 & 0 & 0 & 0 \\
\hline 6 & 0 & 0 & 0 & 0 & 0 & 1 & 0 & 0 & 0 & 1 & 0 & 0 & 0 & 0 & 1 & 0 & 0 & 0 & 0 & 0 \\
\hline 7 & 0 & 0 & 0 & 0 & 0 & 0 & 1 & 0 & 1 & 0 & 0 & 1 & 0 & 0 & 0 & 0 & 0 & 0 & 0 & 0 \\
\hline 8 & 0 & 0 & 0 & 0 & 0 & 0 & 0 & 1 & 1 & 0 & 0 & 1 & 0 & 0 & 0 & 0 & 0 & 0 & 0 & 0 \\
\hline
\end{tabular}

sites. The information of the production flows of each product is given in Table 1 . The value of one indicates the path of manufacturing a product. Take Product 4 as an example here. The body of this product is produced in Body shop 4 and then, it has the ability to be painted in Paint shops 1 and 3 and assembled in Assembler shops 5, 6, 7, and 8, which are all shown in Table 1 with number 1 . It should be noted that based on the product flow and production planning, this product is produced in one or more than one of these paint shops and assembler shops.

The company is active $24 \mathrm{~h}$ a day in three shifts starting from 7:30 AM to 3:30 PM, 3:30 PM to 11:45 PM, and 11:45 PM to 7:30 AM, respectively. Table 2 presents the cycle time and active shifts of each production hall. The resulting distributions for each production hall were validated by the KolmogorovSmirnov test for their goodness of fit. Furthermore, the logistic path between the production halls and the storage space capacities are shown in Tables 3 and 4 , respectively.

The present study aimed to optimize the performance of the system. To this end, some performance measures necessary for the company are defined. These variables represent the outputs aiming to collect information based on the purpose of the study. It should 
Table 2. The cycle time and active shifts of each production hall.

\begin{tabular}{llc}
\hline $\begin{array}{c}\text { Production } \\
\text { hall }\end{array}$ & \multicolumn{1}{c}{ Cycle time } & $\begin{array}{c}\text { Active } \\
\text { shift }\end{array}$ \\
\hline Body shop 1 & Uniform $(168.66,171.14)$ & 1 \\
Body shop 2 & Uniform $(148.83,151.87)$ & $1-3$ \\
Body shop 3 & Uniform $(259.81,263.09)$ & $1-2$ \\
Body shop 4 & Uniform $(176.66,179.14)$ & $1-2-3$ \\
Body shop 5 & Uniform $(118.68,122.62)$ & $1-2-3$ \\
Body shop 6 & Uniform $(423.35,426.95)$ & 1 \\
Body shop 7 & Uniform $(538.10,542.20)$ & $1-2$ \\
Body shop 8 & Uniform $(519.41,523.69)$ & $1-2$ \\
Paint shop 1 & Uniform $(94.23,97.87)$ & $1-2-3$ \\
Paint shop 2 & Uniform $(84.18,88.12)$ & $1-2-3$ \\
Paint shop 3 & Uniform $(142.13,146.27)$ & $1-2$ \\
Assembler shop 1 & Uniform $(262.99,265.31)$ & $1-2$ \\
Assembler shop 2 & Uniform $(265.89,267.51)$ & $1-3$ \\
Assembler shop 3 & Uniform $(168.31,171.59)$ & 1 \\
Assembler shop 4 & Uniform $(108.77,112.03)$ & $1-2-3$ \\
Assembler shop 5 & Uniform $(316.91,319.69)$ & 1 \\
Assembler shop 6 & Uniform $(409.86,412.34)$ & $1-2$ \\
Assembler shop 7 & Uniform $(508.79,511.01)$ & 1 \\
Assembler shop 8 & Uniform $(295.76,298.14)$ & $1-2$ \\
Assembler shop 9 & Uniform $(151.88,154.12)$ & $1-2$ \\
\hline & &
\end{tabular}

be noted that they are determined according to two main data sources. First of all, historical data is one of the crucial resources for collecting the required information; the mentioned data refer to databases that contain the process of the last 40 years and information such as profit and loss, number of products produced, logistic processes, etc. Secondly, opinions and expertise of experts working in the company are the other essential resource. These people manage production processes with expertise on a daily basis and they are experts in various fields of production including planning, organizing, engineering, managing logistics, controlling product flow, and managing resource allocation. Table 5 presents these variables with the current values of the manufacturing system.

Furthermore, based on the historical data and expert opinions, several practical factors are also determined and they have a great impact over the response variables of the productive system. The production of product 3 is considered the most crucial factor in increasing the production value; thus, the company attempts to increase the output number for this product as the most valuable product. Therefore, increasing the production planning of product 3 may have a positive effect on the essential goals of the company. On the other hand, increasing the production of products fabricated below the sufficient production capacity (e.g., product 6) can be useful in the volume of production. According to shift works, production scheduling, and capacity measurements of production lines, minimum and maximum numbers of products 3 and 6 produced are $(200,350)$ and $(60,220)$, respectively. Moreover, minimization of non-mechanized stocks, including WBS 4 and WBS 7, is regarded as another substantial factor that the company must always seek to improve, as well. These stocks are caused by the production speed of production halls, work shifts, and differences in capacity of production

Table 3. The logistic path between the production halls.

\begin{tabular}{cllcccccc}
\hline $\begin{array}{c}\text { Transportation } \\
\text { network }\end{array}$ & $\begin{array}{c}\text { Preceding } \\
\text { hall }\end{array}$ & \multicolumn{1}{c}{$\begin{array}{c}\text { Following } \\
\text { hall }\end{array}$} & $\begin{array}{c}\text { Load } \\
\text { time } \\
(\mathbf{s e c})\end{array}$ & $\begin{array}{c}\text { Unload } \\
\text { time } \\
(\mathbf{s e c})\end{array}$ & $\begin{array}{c}\text { Load } \\
\text { quantity }\end{array}$ & $\begin{array}{c}\text { Number } \\
\text { of } \\
\text { trucks }\end{array}$ & $\begin{array}{c}\text { Distance } \\
(\mathbf{k m})\end{array}$ & $\begin{array}{c}\text { Speed } \\
(\mathbf{k m} / \mathbf{h})\end{array}$ \\
\hline 1 & WBS 4 & Paint shop 1 & 60 & 58 & 2 & 5 & 1.2 & 20 \\
2 & WBS 4 & Paint shop 3 & 60 & 58 & 2 & 8 & 2.7 & 25 \\
3 & Body shop 7 & Paint shop 1 & 120 & 130 & 1 & 5 & 0.1 & 5 \\
4 & WBS 8 & Paint shop 1 & 60 & 58 & 2 & 2 & 0.9 & 15 \\
5 & PBS 1 & SKD hall & 90 & 65 & 2 & 5 & 2.2 & 25 \\
6 & PBS 2 & SKD hall & 75 & 75 & 2 & 5 & 2 & 20 \\
7 & PBS 3 & SKD hall & 75 & 75 & 2 & 5 & 3 & 30 \\
8 & SKD hall & Assembler shop 5 & 1800 & 1800 & 11 & 30 & 924 & 90 \\
10 & SKD hall & Assembler shop 6 & 1740 & 1740 & 11 & 42 & 526 & 85 \\
11 & SKD hall & Assemble shop 7 & 1920 & 1820 & 11 & 6 & 236 & 90 \\
\hline
\end{tabular}

Note: WBS: Without paint Body Stock; PBS: Painted Body Stock; SKD: Semi-Knocked-Down. 
Table 4. The storage space capacities.

\begin{tabular}{|c|c|c|c|}
\hline Hall & Preceding hall & Following hall & Capacity \\
\hline WBS 1 & Body shop 1 & Paint shop 3 & 100 \\
\hline WBS 2 & $\begin{array}{l}\text { Body shop } 2 \\
\text { Body shop } 3 \\
\text { Body shop } 6 \\
\text { WBS } 5\end{array}$ & $\begin{array}{l}\text { Paint shop } 1 \\
\text { Paint shop } 2\end{array}$ & 130 \\
\hline WBS 5 & Body shop 5 & WBS 2 & 100 \\
\hline WBS 4 & Body shop 4 & $\begin{array}{l}\text { Paint shop } 1 \\
\text { Paint shop } 3\end{array}$ & 20 \\
\hline WBS 8 & Body shop 8 & Paint shop 1 & 100 \\
\hline PBS 1 & Paint shop 1 & $\begin{array}{l}\text { Assembler shop } 1 \\
\text { Assembler shop } 2 \\
\text { SKD hall }\end{array}$ & 195 \\
\hline PBS 2 & Paint shop 2 & $\begin{array}{l}\text { Assembler shop } 2 \\
\text { Assembler shop } 4 \\
\text { SKD hall }\end{array}$ & 155 \\
\hline PBS 3 & Paint shop 3 & $\begin{array}{l}\text { Assembler shop } 3 \\
\text { SKD hall }\end{array}$ & 135 \\
\hline Conveyor 1 & WBS 1 & Paint shop 3 & 5 \\
\hline Conveyor 2 & PBS 3 & Assembler shop 3 & 15 \\
\hline Conveyor 3 & Body shop 2 & WBS 2 & 17 \\
\hline Conveyor 4 & Body shop 3 & WBS 2 & 17 \\
\hline Conveyor 5 & Body shop 6 & WBS 2 & 15 \\
\hline Conveyor 6 & WBS 5 & WBS 2 & 15 \\
\hline Conveyor 7 & WBS 2 & Paint shop 1 & 40 \\
\hline Conveyor 8 & WBS 2 & Paint shop 2 & 60 \\
\hline Conveyor 9 & PBS 1 & Assembler shop 1 & 2 \\
\hline Conveyor 10 & PBS 1 & Assembler shop 2 & 2 \\
\hline Conveyor 11 & PBS 2 & Assembler shop 2 & 10 \\
\hline Conveyor 12 & PBS 2 & Assembler shop 4 & 60 \\
\hline
\end{tabular}

Note: WBS: Without paint Body Stock; PBS: Painted Body Stock;

SKD: Semi-Knocked-Down.

Table 5. The response variables.

\begin{tabular}{clc}
\hline Variable & \multicolumn{1}{c}{ Description } & Current state \\
\hline$Y_{1}$ & Total production profit & $\$ 2,368,750.00$ \\
$Y_{2}$ & Amount of production & 2045 \\
$Y_{3}$ & Average productivity of production halls & $97.27 \%$ \\
$Y_{4}$ & Number of trucks carrying the body & 299 \\
$Y_{5}$ & Number of semi-finished products during the process & 482 \\
\hline
\end{tabular}

lines in the origin and destination halls, which can reach the maximum amount of 120 bodies due to the space allocated to these bodies. This can be rectified by optimizing the production process, leading to minimum amount, that is, zero. Moreover, reduction of the cycle time of Assembler shop 4 leads to an increase in the production rate without additional cost in this production hall. This factor reduces the logistics between the production halls and capital sleep. As the level of automation in this hall is high and does not 
Table 6. The factors and levels.

\begin{tabular}{clcc}
\hline & & \multicolumn{2}{c}{ Level } \\
\cline { 3 - 4 } Factor & \multicolumn{1}{c}{ Description } & Low (-) & High (+) \\
\hline$x_{1}$ & Production planning of product 3 & 200 & 350 \\
$x_{2}$ & Production planning of product 6 & 60 & 220 \\
$x_{3}$ & Non-mechanized stocks & 0 & 120 \\
$x_{4}$ & Assembler shop 4 cycle time & 92 & 115 \\
\hline
\end{tabular}

Table 7. The scenario design and the results of simulation modeling.

\begin{tabular}{|c|c|c|c|c|c|c|c|c|c|}
\hline \multirow[b]{2}{*}{ Scenario } & \multicolumn{4}{|c|}{ Factors } & \multicolumn{5}{|c|}{ Response } \\
\hline & $x_{1}$ & $x_{2}$ & $x_{3}$ & $x_{4}$ & $Y_{1}$ & $Y_{2}$ & $Y_{3}$ & $Y_{4}$ & $Y_{5}$ \\
\hline 1 & - & - & - & - & $\$ 2,154,250.00$ & 1652 & $\% 81.52$ & 229 & 390 \\
\hline 2 & + & - & - & - & $\$ 2,671,225.00$ & 1792 & $\% 84.25$ & 197 & 355 \\
\hline 3 & - & + & - & - & $\$ 2,220,875.00$ & 1662 & $\% 90.71$ & 224 & 494 \\
\hline 4 & + & + & - & - & $\$ 2,743,875.00$ & 1832 & $\% 93.47$ & 174 & 621 \\
\hline 5 & - & - & + & - & $\$ 2,368,150.00$ & 1954 & $\% 96.63$ & 229 & 477 \\
\hline 6 & + & - & + & - & $\$ 2,538,875.00$ & 1760 & $\% 90.30$ & 197 & 512 \\
\hline 7 & - & + & + & - & $\$ 2,412,250.00$ & 1908 & $\% 95.05$ & 224 & 641 \\
\hline 8 & + & + & + & - & $\$ 2,699,500.00$ & 1770 & $\% 91.95$ & 174 & 585 \\
\hline 9 & - & - & - & + & $\$ 2,148,475.00$ & 1634 & $\% 81.02$ & 229 & 422 \\
\hline 10 & + & - & - & + & $\$ 2,678,050.00$ & 1802 & $\% 85.45$ & 197 & 369 \\
\hline 11 & - & + & - & + & $\$ 2,204,875.00$ & 1515 & $\% 88.10$ & 224 & 587 \\
\hline 12 & + & + & - & + & $\$ 2,652,125.00$ & 1663 & $\% 89.44$ & 174 & 578 \\
\hline 13 & - & - & + & + & $\$ 2,368,750.00$ & 1989 & $\% 97.27$ & 229 & 482 \\
\hline 14 & + & - & + & + & $\$ 2,627,375.00$ & 1818 & $\% 92.25$ & 197 & 563 \\
\hline 15 & - & + & + & + & $\$ 2,401,375.00$ & 1836 & $\% 94.87$ & 224 & 690 \\
\hline 16 & + & + & + & + & $\$ 2,671,875.00$ & 1763 & $\% 92.13$ & 174 & 671 \\
\hline
\end{tabular}

depend on human resources for speed changes, its speed may easily change and reach minimum and maximum values of 92 and 115, respectively. Table 6 summarizes the factors and levels selected for the experimental design.

\subsection{Results}

The present study used ED in order to build the model and simulate the system. Also, a computer simulation is utilized for solving the problem since it provides a systematic plan for evaluating different production scenarios based on the generated and objective data in order to assist the decision-maker [25]. Figure 3 illustrates the simulation model of the manufacturing system.

After developing a computer simulation model, evaluating the validity and accuracy of the simulation model is of considerable significance since the model should have a similar function to the real world in order to extend the results. Therefore, the many capabilities of the ED software are used to verify the model, followed by performing the paired t-test for validation purposes. Further, the warm-up time (i.e., the time it takes for a non-terminate system to reach a relatively stable state) is set at $20 \mathrm{~h}$ based on the throughput/hour diagram. Then, the scenarios as well as the DOE method are presented in Tables 5 and 6 . Table 7 shows the scenario design and the results of simulation modeling. Each scenario was simulated for $24 \mathrm{~h}, 100$ replications, and the average of 100 runs used accordingly.

According to the experts' opinions, four input indicators namely the production planning of product 3 $\left(x_{1}\right)$, the production planning of product $6\left(x_{2}\right)$, the 


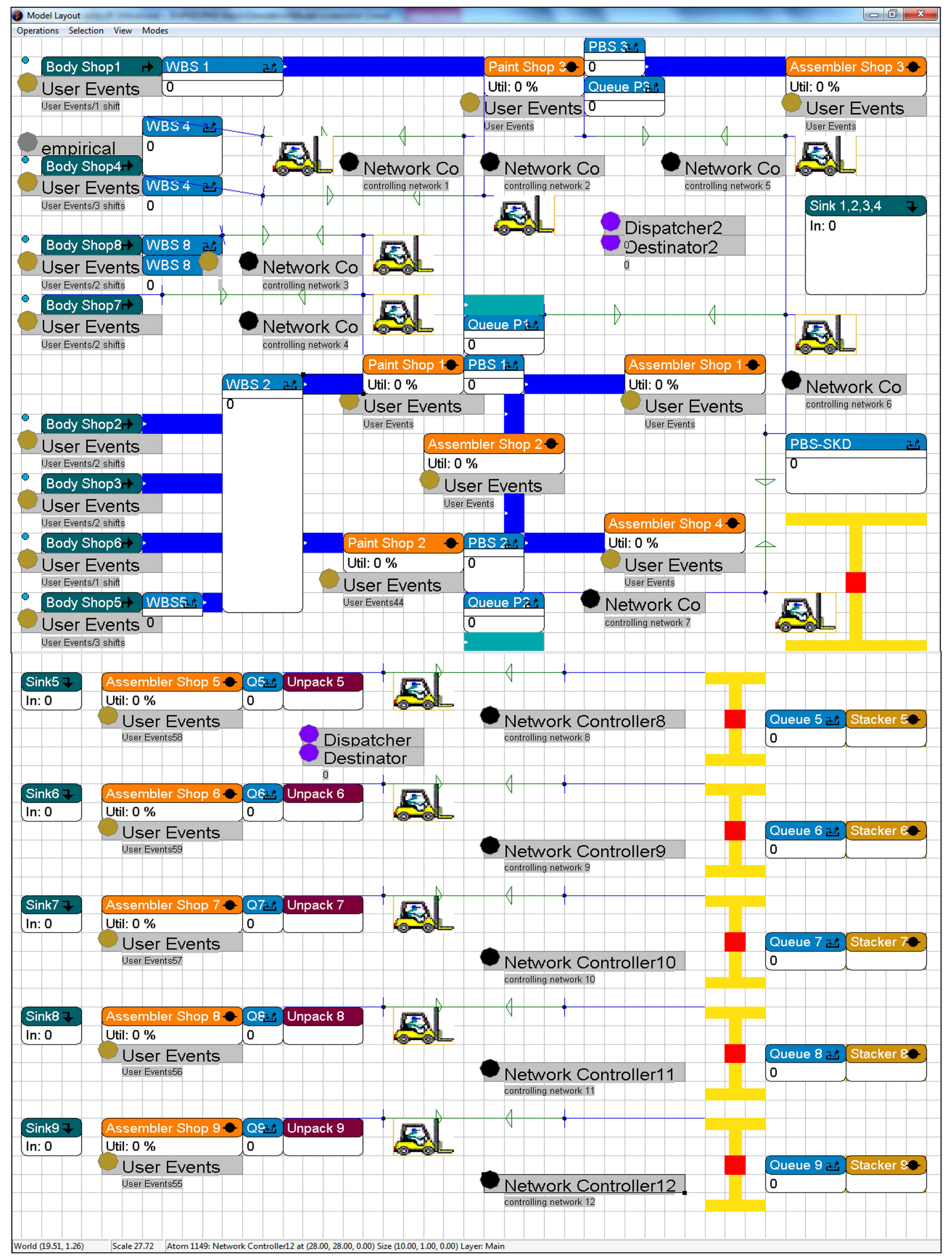

Figure 3. The simulation model of the manufacturing system in ED software. 
Table 8. Weight of input indicators based on the SWARA method.

\begin{tabular}{ccccc}
\hline Indicator & $\begin{array}{c}\text { Comparative importance } \\
\text { of average value }(\boldsymbol{S})\end{array}$ & $\begin{array}{c}\text { Coefficient } \\
(\boldsymbol{K})\end{array}$ & $\begin{array}{c}\text { Recalculated } \\
\text { weight }(\boldsymbol{q})\end{array}$ & $\begin{array}{c}\text { Weight } \\
(\boldsymbol{W})\end{array}$ \\
\hline$x_{1}$ & 0.2433 & 1 & 1 & 0.3704 \\
$x_{2}$ & 0.1944 & 1.2433 & 0.8043 & 0.2979 \\
$x_{3}$ & 0.2299 & 1.4377 & 0.5594 & 0.2072 \\
$x_{4}$ & & 1.6677 & 0.3354 & 0.1242 \\
\hline
\end{tabular}

Table 9. Weight of output indicators based on the SWARA method.

\begin{tabular}{ccccc}
\hline Indicator & $\begin{array}{c}\text { Comparative importance } \\
\text { of average value }(\boldsymbol{S})\end{array}$ & $\begin{array}{c}\text { Coefficient } \\
(\boldsymbol{K})\end{array}$ & $\begin{array}{c}\text { Recalculated weight } \\
(\boldsymbol{q})\end{array}$ & $\begin{array}{c}\text { Weight } \\
(\boldsymbol{W})\end{array}$ \\
\hline$Y_{1}$ & 0.2521 & 1 & 1 & 0.3436 \\
$Y_{2}$ & 0.1942 & 1.2521 & 0.7986 & 0.2744 \\
$Y_{3}$ & 0.1375 & 1.4463 & 0.5521 & 0.1897 \\
$Y_{4}$ & 0.0721 & 1.5839 & 0.3486 & 0.1198 \\
$Y_{5}$ & & 1.6560 & 0.2105 & 0.0723 \\
\hline
\end{tabular}

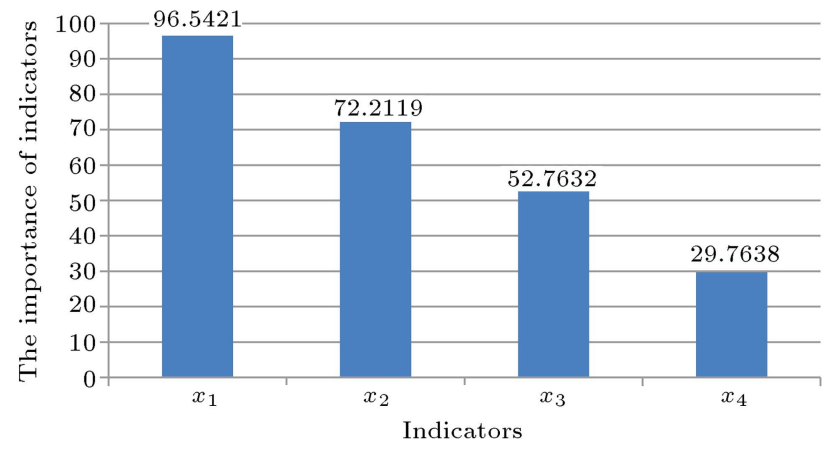

Figure 4. The importance of input indicators.

non-mechanized stocks $\left(x_{3}\right)$, and the cycle time of Assembler shop $4\left(x_{4}\right)$ were investigated in the scenarios. Furthermore, five output indicators including total production profit $\left(y_{1}\right)$, volume of production $\left(y_{2}\right)$, average productivity of production halls $\left(y_{3}\right)$, number of trucks carrying the body $\left(y_{4}\right)$, and number of semi-finished products during the process $\left(y_{5}\right)$ were determined for performance optimization as the output indicators. In order to investigate the importance of input and output indicators, the statistical population was selected based on the expertise of the experts affiliated with Iran Khodro Automotive Company. Qualification requirements include three characteristics: high education, significant work experience (at least 10 years of work experience), and managerial experience. Therefore, considering the mentioned conditions, out of 70 experts working in this company, 33 qualified ones were selected. Afterwards, SWARA was used to determine the weights of input and output indicators according to expert opinions in the score range of 0 to 100 via questionnaire. Validity of questionnaire was confirmed by experts and reliability was calculated

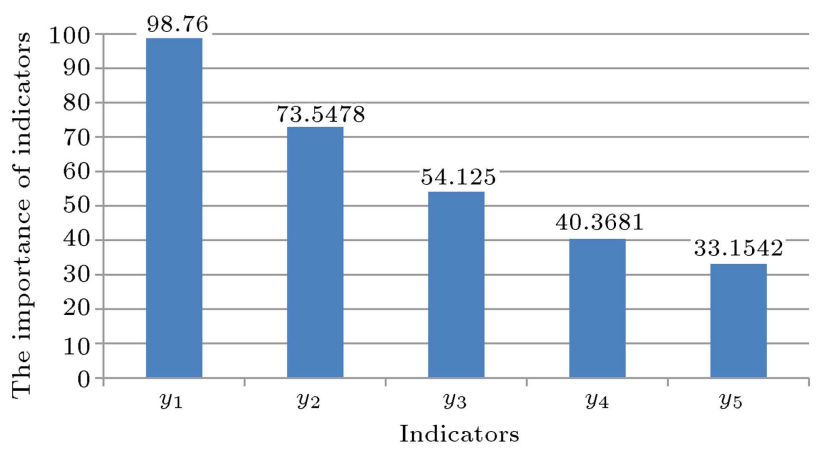

Figure 5. The importance of output indicators.

with Cronbach's Alpha in SPSS software. The obtained reliability was equal to 0.814 , pointing to the acceptability of the questionnaire. According to the average importance of the indicators assigned by the experts, Figures 4 and 5 show the importance of the input and output indicators.

According to the importance of input and output indicators, the relative importance between the indicators is determined in pairs. Afterwards, based on the steps expressed in Section 2.3, the final weight of each indicator is determined. Tables 8 and 9 present the weights of input and output indicators. The efficiency values and the ranking of DMUs, namely the scenarios, are provided in Table 10.

The steady status of the company is based on two objectives: the amount of production and productivity of the equipment. This situation has been achieved by the repeated changes made in production planning and trail-error method over three years. Also, the performance has proved to be favorable in relation to the current strategy of the organization. Moreover, unpredictable events in Iran's automobile industry 
Table 10. The efficiency values and the ranking of DMUs.

\begin{tabular}{ccc}
\hline DMU/Scenario & Efficiency & Rank \\
\hline$D M U_{1}$ & 0.8905 & 7 \\
$D M U_{2}$ & 0.9624 & 3 \\
$D M U_{3}$ & 0.9159 & 5 \\
$D M U_{4}$ & 1 & 1 \\
$D M U_{5}$ & 0.0526 & 9 \\
$D M U_{6}$ & 0.0476 & 11 \\
$D M U_{7}$ & 0.0382 & 13 \\
$D M U_{8}$ & 0.0340 & 15 \\
$D M U_{9}$ & 0.8869 & 8 \\
$D M U_{10}$ & 0.9661 & 2 \\
$D M U_{11}$ & 0.8943 & 6 \\
$D M U_{12}$ & 0.9466 & 4 \\
$D M U_{13}$ & 0.0500 & 10 \\
$D M U_{14}$ & 0.0462 & 12 \\
$D M U_{15}$ & 0.0349 & 14 \\
$D M U_{16}$ & 0.0312 & 16 \\
\hline
\end{tabular}

Note: DMU: Decision-Making Unit.

have increased the fixed prices of the automobiles and thus, changed the goals of the company in terms of production.

These goals include increasing the profit of the total production of profitable products, reducing lowefficiency manufacturing sites, moving to green logistics, and reducing semi-finished products during the process alongside maintaining the production numbers. Therefore, to achieve these new goals, this study evaluated the performance optimization of current status and the proposed scenarios and obtained efficient scenarios based on the previous years of experience, along with the simulation optimization method. Table 7 represents the effect of decreasing and increasing each input indicator on the output indicators of the DMUs.

According to Table 10, Scenario 13 indicates the current status of the organization, which is ranked tenth. The profitable product is at its maximum level in an efficient scenario. However, the amount of production indicates a decrease compared to Scenario 13, which is still highly rated due to a significant increase in the production profits and is highly essential to the status and performance of the organization. In designing and simulating this scenario, SKD products as well as Kermanshah site (Assembler shop 6) reduced to a site due to high logistical requirements and meager profits and their supply sources were employed to increase the production of profitable products. Another advantage of this scenario is the reduction of road traffic to $526 \mathrm{~km}$, which is a big step toward social responsibility and green logistics.

In Scenario 10, which is ranked second, the total production profit, the number of semi-finished products during the process, and the logistical factors point to the significant improvement compared to the current situation, while the final number of products and the production profit experience a decrease compared to the fourth scenario. Scenario 10 is one of the best scenarios in terms of reducing the semi-finished products during the process. On the other hand, Scenario 16 is at the bottom of the rankings. In this scenario, the production performance and the productivity of the equipment are reduced, while the stock levels increase despite the increase in the number of all the resources.

\section{Discussion}

This section examines the effect of the combined methods in the proposed approach in comparison to other methods in the literature for optimization of different PS parts. One of the crucial preferences of this approach is employing the advantages of DES, DOE, DEA, and MADM methods simultaneously. Although DES is one of the most effective and useful tools in manufacturing industries, the use of this method without suitable optimization tools does not ensure comprehensive and accurate analysis in research studies.

Previous studies have employed DES method to assess the green logistics practices in the automotive industry [2], enhance production scheduling procedures [3], implement a simulation-based online production planning system [6], demonstrate the applicability of DES to monitoring the performance of production lines [8], construct simulation models of PS [9], evaluate and compare different production planning [14], and suggest production planning in the automotive industry [16]. In their study, the results were evaluated without a suitable tool for production scenarios.

One of the most widely used tools for producing scenarios is DOE. This method enables us to analyze the simulation models systematically and present an appropriate analysis of the results and to, finally, choose the optimal scenario for the case study. For example, Zahraee et al. proposed an integrated computer simulation and DOE method in a continuous production line [7]. Although this tool helps exceedingly to close the optimal scenario, it cannot be an accurate tool for selecting the optimal scenario. Thus, in order to compare the proposed approach using only the DOE method in simulation, Table 7 has been constructed with $2^{k}$ factorial design in MINITAB software. Table 11 shows the effectiveness of factors for each response variable.

According to Table 11, given that $x_{1}$ (production planning of product 3 ) and $x_{3}$ (non-mechanized stocks) factors have the most significant effect on response variables and upon increasing these factors and de- 
Table 11. Effectiveness of response variables.

\begin{tabular}{ccccc}
\hline \multirow{2}{*}{$\begin{array}{c}\text { Response } \\
\text { variable }\end{array}$} & \multicolumn{4}{c}{$\begin{array}{c}\text { Propriety of } \\
\text { effectiveness }\end{array}$} \\
\cline { 2 - 5 } & $\boldsymbol{x}_{\boldsymbol{1}}$ & $\boldsymbol{x}_{\boldsymbol{2}}$ & $\boldsymbol{x}_{\boldsymbol{3}}$ & $\boldsymbol{x}_{\boldsymbol{4}}$ \\
\hline$Y_{1}$ & 1 & 2 & 3 & 4 \\
$Y_{2}$ & 1 & 2 & 3 & 4 \\
$Y_{3}$ & 4 & 3 & 2 & 1 \\
$Y_{4}$ & 2 & 3 & 1 & 4 \\
$Y_{5}$ & 2 & 3 & 1 & 4 \\
\hline
\end{tabular}

creasing $x_{2}$ (production planning of product 6 ) and $x_{4}$ (cycle time of assembler shop 4), the best scenario was obtained. Thus, Scenario 6 was found to be efficient. According to the calculation conducted as part of the proposed approach implementation, this scenario was ranked eleventh. Given the extreme difference among $Y_{1}$ (total production profit), $Y_{2}$ (amount of production), and $Y_{5}$ (number of semi-finished products during the process) variables, which is a matter of importance for the company, the scenarios were compared with the efficient scenario. DOE method is not able to rank the scenarios in terms of other output variables and does not consider the degree of importance of the inputs and outputs in its calculations. Therefore, it can only provide some comparative analysis of the results obtained from the degree of effectiveness of each factor in the response variables and suggest the optimal scenario, which may not necessarily be the best.

On the other hand, DEA is one of the most useful methods in terms of performance evaluation and scenario ranking in simulation models. In previous studies, the combination of simulation and DEA methods is used for vendor selection [23], group consensus ranking [24], and facility layout design problem [25]. Although DEA is one of the best optimization methods in scenario ranking, it is unable to produce scenarios and can only design scenarios based on expert opinions. In order to illustrate the importance of the DOE method in producing scenarios, Table 12 shows sixteen scenarios based on expert opinions and they are solved through simulation and DEA methods.

According to Table 12, Scenario 7 is efficient. Compared to the same scenario in the proposed approach, Scenario 3 in Table 7 is close to the scenario which is efficient in Table 12 . In this scenario, $x_{1}$ (production planning of product 3 ), $x_{3}$ (production planning of product 3 ), and $x_{4}$ (non-mechanized stocks) factors have their lowest values and are ranked fifth. It should be noted that $Y_{1}$ (total production profit) and $Y_{2}$ (amount of production) variables, which are the most crucial outputs for the company, have lower values than the ones in the efficient scenario and DEA is not capable of considering the weights of the inputs and the outputs concerning the opinions of the experts

Table 12. The scenario design with expert opinions.

\begin{tabular}{|c|c|c|c|c|c|c|c|c|c|c|c|}
\hline \multirow{2}{*}{ Scenario } & \multicolumn{4}{|c|}{ Factors } & \multicolumn{5}{|c|}{ Response } & \multirow{2}{*}{ Efficiency } & \multirow{2}{*}{ Rank } \\
\hline & $\boldsymbol{x}_{1}$ & $\boldsymbol{x}_{2}$ & $\boldsymbol{x}_{3}$ & $\boldsymbol{x}_{4}$ & $Y_{1}$ & $Y_{2}$ & $Y_{3}$ & $Y_{4}$ & $Y_{5}$ & & \\
\hline 1 & 210 & 60 & 0 & 95 & $\$ 2,152,200.00$ & 1630 & $\% 80.32$ & 229 & 390 & 0.95 & 3 \\
\hline 2 & 310 & 70 & 0 & 95 & $\$ 2,670,125.00$ & 1781 & $\% 83.1$ & 197 & 355 & 0.97 & 2 \\
\hline 3 & 210 & 220 & 100 & 95 & $\$ 2,410,578.00$ & 1912 & $\% 95.15$ & 224 & 641 & 0.04 & 13 \\
\hline 4 & 350 & 220 & 0 & 95 & $\$ 2,732,754.00$ & 1795 & $\% 91.7$ & 174 & 621 & 0.81 & 4 \\
\hline 5 & 210 & 70 & 100 & 95 & $\$ 2,468,054.00$ & 1905 & $\% 96.1$ & 229 & 477 & 0.055 & 9 \\
\hline 6 & 350 & 70 & 100 & 95 & $\$ 2,549,521.00$ & 1752 & $\% 91.7$ & 197 & 512 & 0.04 & 11 \\
\hline 7 & 210 & 220 & 0 & 95 & $\$ 2,221,073.00$ & 1652 & $\% 91.1$ & 224 & 494 & 1 & 1 \\
\hline 8 & 350 & 220 & 100 & 95 & $\$ 2,698,721.00$ & 1792 & $\% 92.3$ & 174 & 585 & 0.03 & 15 \\
\hline 9 & 210 & 70 & 0 & 115 & $\$ 2,152,469.00$ & 1638 & $\% 80.02$ & 229 & 422 & 0.75 & 8 \\
\hline 10 & 350 & 70 & 0 & 115 & $\$ 2,598,254.00$ & 1798 & $\% 87.45$ & 197 & 369 & 0.76 & 7 \\
\hline 11 & 210 & 220 & 0 & 115 & $\$ 2,154,789.00$ & 1545 & $\% 89.5$ & 224 & 587 & 0.78 & 5 \\
\hline 12 & 350 & 220 & 0 & 115 & $\$ 2,635,816.00$ & 1697 & $\% 91.1$ & 174 & 578 & 0.78 & 6 \\
\hline 13 & 210 & 70 & 100 & 115 & $\$ 2,368,212.00$ & 1995 & $\% 96.22$ & 229 & 482 & 0.05 & 10 \\
\hline 14 & 350 & 70 & 100 & 115 & $\$ 2,598,757.00$ & 1795 & $\% 92.5$ & 197 & 563 & 0.04 & 12 \\
\hline 15 & 210 & 220 & 100 & 115 & $\$ 2,458,981.00$ & 1846 & $\% 93.65$ & 224 & 690 & 0.03 & 14 \\
\hline 16 & 350 & 220 & 100 & 115 & $\$ 2,692,541.00$ & 1782 & $\% 91.05$ & 174 & 671 & 0.03 & 16 \\
\hline
\end{tabular}


Table 13. The efficiency values and the ranking of DMUs without weights.

\begin{tabular}{lcc}
\hline DMU/Scenario & Efficiency & Rank \\
\hline$D M U_{1}$ & 0.93 & 3 \\
$D M U_{2}$ & 1.00 & 1 \\
$D M U_{3}$ & 0.96 & 2 \\
$D M U_{4}$ & 0.82 & 4 \\
$D M U_{5}$ & 0.05 & 9 \\
$D M U_{6}$ & 0.04 & 11 \\
$D M U_{7}$ & 0.04 & 13 \\
$D M U_{8}$ & 0.03 & 15 \\
$D M U_{9}$ & 0.74 & 7 \\
$D M U_{10}$ & 0.80 & 5 \\
$D M U_{11}$ & 0.73 & 8 \\
$D M U_{12}$ & 0.79 & 6 \\
$D M U_{13}$ & 0.05 & 10 \\
$D M U_{14}$ & 0.04 & 12 \\
$D M U_{15}$ & 0.03 & 14 \\
$D M U_{16}$ & 0.03 & 16 \\
\hline
\end{tabular}

Note: DMU: Decision-Making Unit

of the company. Furthermore, in these 16 scenarios, not only is Scenario 4 in Table 7 not considered, but also some scenarios are the same for the performance results in Table 12. Therefore, the combination of DEA and DOE methods prevents these problems.

Previous research has attempted to resolve this weakness and use the benefits of simulation, DEA, and DOE methods simultaneously. The combinations of these methods have been used to improve the performance of the PS in the automobile spare parts manufacturer [11] and to evaluate the performance of the educational system [17]. Although this combination improves the optimization process, it still has a weakness in considering the input and output weights in calculations. In order to illustrate the importance of this subject, Table 7 shows the calculation regardless of the weight of the inputs and outputs. Besides, the results are given in Table 13.

As can be seen in Table 13, the second scenario was found to be efficient. In comparison with the proposed approach that identified the fourth scenario as efficient, the efficiency of the second scenario was reduced by $3 \%$ in terms of both $Y_{1}$ (total production profit) and $Y_{2}$ (amount of production) variables. These two variables are crucial for the company and virtually, it will not be the most efficient scenario. Therefore, the use of the MADM method (SWARA) creates at least a $3 \%$ improvement, which is a significant percentage in the industry.

With applying SWARA in the proposed approach, the maximum outputs of $Y_{1}$ and $Y_{2}$ and the minimum inputs of $X_{3}$ and $X_{4}$ as a optimal scenario was obtained, which we would not have reached this scenario if this method was not used.

To recapitulate, various production processes including the capacity of production halls, logistics, resource allocation, production strategies in accordance with the goals of the organization, production planning, and flow of products were considered simultaneously in the simulation model, which cannot be found in previous studies. Moreover, the optimization of the simulation model is a combination of DOE, DEA, and SWARA methods, which is essential to perform precise analysis. DOE helps to produce different scenarios according to the strategic goals of the organization. In addition, SWARA provided the weight of input and output indicators, leading to accurate calculation of the efficient scenario in DEA. Some characteristics of the proposed method are also compared with those of the aforementioned methods, as listed in Table 14 .

\section{Conclusion}

In general, increasing the production efficiency, determining the useful methods for optimizing the performance of different parts of Production System (PS), and measuring the impact of any changes in every element in line with the strategic goals of the organization are the major concerns of the manufacturing companies. Optimization of the PS can help each manufacturer resolve failures, reduce transportation costs, optimize production lines, ensure the continuity of the processes from supply to sales, and eventually, evade the shocking variations in the PS. In other words, optimization of different parts of production processes provides theoretical and practical overviews. The present study aimed to investigate the optimization of different PS parts such as production strategies, resource allocation, logistics and production planning, and flow of products. Further, the proposed approach was evaluated in a case study related to the automobile manufacturing industry in Iran.

As mentioned earlier, the efficiency optimization for PS has received less attention in previous studies. In other words, previous studies have focused on some parts of PS including the production line [7], or only used the simulation approach with the Desin Of Experiment (DOE) or Data Envelopment Analysis (DEA) methods [23]. In addition, these studies optimize the process by basic DEA model [36]. However, the algorithm of the present study dealing with the optimization of performance in different parts of PS with integrated new methods for the first time maximizes the productivity of production process and the total profit, while it minimizes the logistic resources and develops the simulation optimization approach. After 
Table 14. The comparative characteristics of different methods.

\begin{tabular}{|c|c|c|c|c|c|c|c|c|c|}
\hline \multirow[b]{2}{*}{ Methods } & \multicolumn{6}{|c|}{$\begin{array}{l}\text { Considering different } \\
\text { aspects of production } \\
\text { process in } \\
\text { DES simultaneously }\end{array}$} & \multirow[b]{2}{*}{$\begin{array}{l}\text { Designing } \\
\text { scenarios with } \\
\text { regard to } \\
\text { the goals of } \\
\text { organization } \\
\end{array}$} & \multirow[b]{2}{*}{$\begin{array}{c}\text { Prioritizing } \\
\text { the factors by } \\
\text { decision-makers }\end{array}$} & \multirow[b]{2}{*}{$\begin{array}{l}\text { Determining } \\
\text { the efficiency } \\
\text { of production } \\
\text { scenarios }\end{array}$} \\
\hline & 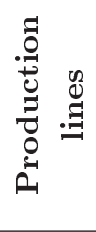 & 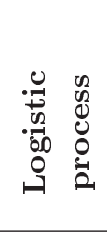 & 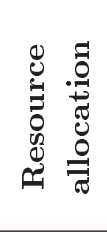 & 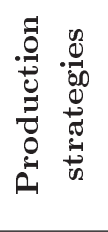 & 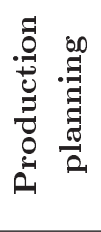 & 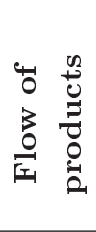 & & & \\
\hline Abdulaziz et al. [2] & $x$ & $\checkmark$ & $\checkmark$ & $x$ & $x$ & $x$ & $x$ & $x$ & $x$ \\
\hline Dumetz et al. [3] & $x$ & $x$ & $\times$ & $\checkmark$ & $\checkmark$ & $\times$ & $\checkmark$ & $\times$ & $\times$ \\
\hline Vaisi and Ebrahimi [11] & $\checkmark$ & $x$ & $x$ & $x$ & $\checkmark$ & $\checkmark$ & $\checkmark$ & $x$ & $\checkmark$ \\
\hline Azadeh et al. [25] & $\times$ & $x$ & $\checkmark$ & $\times$ & $x$ & $\times$ & $\times$ & $\times$ & $\checkmark$ \\
\hline Kaylani and Atieh [14] & $\checkmark$ & $x$ & $\times$ & $x$ & $\checkmark$ & $\checkmark$ & $\checkmark$ & $x$ & $\times$ \\
\hline Gyulai et al. [16] & $\checkmark$ & $x$ & $\times$ & $\times$ & $\checkmark$ & $\times$ & $\checkmark$ & $x$ & $x$ \\
\hline Ebrahiminejad et al. [24] & $x$ & $x$ & $\checkmark$ & $\checkmark$ & $x$ & $x$ & $x$ & $\times$ & $\checkmark$ \\
\hline Marlin and Sohn [17] & $x$ & $x$ & $\times$ & $x$ & $x$ & $\times$ & $\checkmark$ & $x$ & $\checkmark$ \\
\hline Zahraee et al. [7] & $\checkmark$ & $x$ & $\times$ & $\checkmark$ & $x$ & $\checkmark$ & $\checkmark$ & $\times$ & $\times$ \\
\hline Park et al. [23] & $x$ & $x$ & $\checkmark$ & $\checkmark$ & $x$ & $\checkmark$ & $x$ & $\times$ & $\checkmark$ \\
\hline Müller et al. [6] & $\checkmark$ & $\checkmark$ & $\times$ & $\times$ & $\checkmark$ & $\checkmark$ & $x$ & $x$ & $x$ \\
\hline Caterino et al. [8] & $\checkmark$ & $x$ & $\times$ & $\times$ & $\checkmark$ & $\times$ & $\checkmark$ & $x$ & $x$ \\
\hline Pawlewski [9] & $x$ & $x$ & $x$ & $x$ & $\checkmark$ & $\checkmark$ & $\times$ & $\times$ & $\times$ \\
\hline The proposed approach & $\checkmark$ & $\checkmark$ & $\checkmark$ & $\checkmark$ & $\checkmark$ & $\checkmark$ & $\checkmark$ & $\checkmark$ & $\checkmark$ \\
\hline
\end{tabular}

Note: DES: Discrete-Event Simulation.

designing the scenarios with DOE, the weights of the input and output indicators from the DOE were added to the Ratio Efficiency Dominance (RED) model (to increase the accuracy of the performance evaluation) and the model was improved using the Step-wise Weight Assessment Ratio Analysis (SWARA) model taking into account the experts' opinions. Finally, the results were analyzed after calculating the efficiency of Decision-Making Units (DMUs), namely the scenarios designed in the automobile industry in Iran.

Further, the impacts of variation on performance and output indicators were evaluated by DiscreteEvent Simulation (DES) and DOE models. Based on the results, the changes in production planning of product $3\left(x_{1}\right)$, production planning of product 6 $\left(x_{2}\right)$, non-mechanized stocks $\left(x_{3}\right)$, and cycle time of Assembler shop $4\left(x_{4}\right)$ indicators had a significant effect on the efficiency of DMUs. Therefore, appropriate decisions should be adopted according to the number of changes and the initial efficiency of each DMU. For example, with regard to DMU 13, the changes were related to the reduction of cycle time in Assembler shop $4\left(x_{4}\right)$ or non-mechanized stocks $\left(x_{3}\right)$ indices in order to increase the efficiency of the current state. Furthermore, the changes in the production planning of product $3\left(x_{1}\right)$ indicator had a greater impact on the total production profit $\left(Y_{1}\right)$ and the number of trucks carrying the body $\left(Y_{4}\right)$ indicators. Additionally, the amount of the total production profit $\left(Y_{1}\right)$ and the number of trucks carrying the body $\left(Y_{4}\right)$ for DMU4 were optimized upon increasing $x_{1}$ and $x_{2}$. On the other hand, a decrease in the average productivity of production halls $\left(Y_{3}\right)$ could be observed by reducing the values of $x_{3}$ and $x_{4}$ indicators.

In general, the results indicate that the proposed algorithm is a practical instrument for optimizing the production process and it helps manufacturing companies to make efficient decisions, increase their productivity, and decrease the essential problems in every part of PS. In addition, this approach is able to consider the impact of any changes made to the whole system, which can find the optimal solution by ranking the DMUs.

\section{References}

1. Martins, L.M., Fernandes, N.O.G., Varela, M.L.R., et al. "Comparative study of autonomous production control methods using simulation", Simulation Modelling Practice and Theory, 104, 102142 (2020). DOI: 10.1016/j.simpat.2020.102142

2. Abdulaziz, O., Cheng, J.K., Tahar, R.M., et al. "A hy- 
brid simulation model for green logistics assessment in automotive industry", Procedia Engineering, 100, pp. 960-969 (2015). DOI: 10.1016/j.proeng.2015.01.455

3. Dumetz, L., Gaudreault, J., Thomas, A., et al. "A simulation framework for the evaluation of production planning and order management strategies in the sawmilling industry", IFAC-Papers OnLine, 48(3), pp. 622-627 (2015). DOI: 10.1016/j.ifacol.2015.06.151

4. Heidarzadeh, S., Doniavi, A., and Solimanpur, M. "Development of supply chain strategy in the Iranian automotive industry based on system dynamics and game theory", Scientia Iranica, 24(6), pp. 3345-3354 (2017). DOI: $10.24200 /$ sci.2017.4393

5. Vieira, G.E., Kück, M., Frazzon, E., et al. "Evaluating the robustness of production schedules using discreteevent simulation", IFAC-PapersOnLine, 50(1), pp. 7953-7958 (2017). DOI: 10.1016/j.ifacol.2017.08.896

6. Müller, R. (Prof. Dr-Ing), Horauf, L., Speicher, C., et al. "Simulation based online production planning", Procedia Manufacturing, 38, pp. 1473-1480 (2019). DOI: $10.1016 /$ j.promfg.2020.01.140

7. Zahraee, S.M., Rohani, J.M., and Wong, K.Y. "Application of computer simulation experiment and response surface methodology for productivity improvement in a continuous production line: Case study", Journal of King Saud University- Engineering Sciences, 30(3), pp. 207-217 (2018). DOI: 10.1016/j.jksues.2018.04.003

8. Caterino, M., Greco, A., D'Ambra, S., et al. "Simulation techniques for production lines performance control", Procedia Manufacturing, 42, pp. 91-96 (2020). DOI: $10.1016 /$ j.promfg.2020.02.027

9. Pawlewski, P. "Using PFEP for simulation modeling of production system", Procedia Manufacturing, 17, pp. 811-818 (2018). DOI: 10.1016/j.promfg.2018.10.132

10. Motlagh, M.M., Azimi, P., Amiri, M., et al. "An efficient simulation optimization methodology to solve a multi-objective problem in unreliable unbalanced production lines", Expert Systems with Applications, 138, pp. 112-836 (2019). DOI: 10.1016/j.eswa.2019.112836

11. Vaisi, B. and Ebrahimi, A. "Utilizing computer simulation and DEAGP to enhance productivity in a manufacturing system", International Journal of Data Envelopment Analysis, 3(5), pp. 857-866 (2015).

12. Galankashi, M.R., Fallahiarezoudar, E., Moazzami, A., et al. "Performance evaluation of a petrol station queuing system: A simulation-based design of experiments study", Advances in Engineering Software, 92, pp. 1526 (2016). DOI: 10.1016/j.advengsoft.2015.10.004

13. Torabi, M. and Mahlooji, H. "An integrated simulation-DEA approach to multi-criteria ranking of scenarios for execution of operations in a construction project", Iranian Journal of Management Studies, 9(4), pp. 801-827 (2016). DOI: 10.22059/ijms.2017.60097

14. Kaylani, H. and Atieh, A.M. "Simulation approach to enhance production scheduling procedures at a pharmaceutical company with large product mix", Procedia CIRP, 41, pp. 411-416 (2016). DOI: 10.1016/j.procir.2015.12.072

15. Kumar, S.R., Nathan, V.N., Ashique, S.I.M., et al. "Productivity enhancement and cycle time reduction in Toyota production system through jishuken activitycase study", Materials Today: Proceedings, 37(2), pp. 964-966 (2020). DOI: 10.1016/j.matpr.2020.06.181

16. Gyulai, D., Pfeiffer, A., Kadar, B., et al. "Simulationbased production planning and execution control for reconfigurable assembly cells", Procedia CIRP, 57, pp. 445-450 (2016). DOI: $10.1016 / \mathrm{j}$.procir.2016.11.077

17. Marlin, B. and Sohn, H. "Using DEA in conjunction with designs of experiments: an approach to assess simulated futures in the Afghan educational system", Journal of Simulation, 10(4), pp. 272-282 (2017). DOI: $10.1057 /$ jos.2015.14

18. Berenguer, G., Lyer, A.V., et al. "Disentangling the efficiency drivers in country-level global health programs: An empirical study", Journal of $O p$ erations Management, 45, pp. 30-43 (2016). DOI: 10.1016/j.jom.2016.05.005

19. Amini, A. and Alinezhad, A. "Integrating DEA and group AHP for efficiency evaluation and the identification of the most efficient DMU", International Journal of Supply and Operations Management, 4(4), pp. 318327 (2017). DOI: 10.22034/2017.4.03

20. Biuki, M., Kazemi, A., and Alinezhad, A. "An integrated location-routing-inventory model for sustainable design of a perishable products supply chain network", Journal of Cleaner Production, 260(10), pp. 1-14 (2020). DOI: 10.1016/j.jclepro.2020.120842

21. Mirmozaffari, M. and Alinezhad, A. "Window analysis using two-stage DEA in heart hospitals", International Conference on Innovation in Science, Engineering Computer and Technology (2017).

22. Zarbakhshnia, N. and Jamali Jaghdani, T. "Sustainable supplier evaluation and selection with a novel two-stage DEA model in the presence of uncontrollable inputs and undesirable outputs: a plastic case study", International Journal of Advanced Manufacturing Technology, 97, pp. 2933-2945 (2018). DOI: 10.1007/s00170-018-2884-y

23. Park, S., Ok, C., and Ha, C. "A stochastic simulation-based holistic evaluation approach with DEA for vendor selection", Computers and Operations Research, 100, pp. 368-378 (2018). DOI: 10.1016/j.cor.2017.08.005

24. Ebrahiminejad, A., Tavana, M., and Sanatos-Arteaga, F.J. "An integrated data envelopment analysis and simulation method for group consensus ranking", Mathematics and Computers in Simulation, 119, pp. 1-17 (2016). DOI: 10.1016/j.matcom.2015.08.022

25. Azadeh, A., Nazari, T., and Charkhand, H. "Optimization of facility layout design problem with safety and environmental factors by stochastic DEA and 
simulation approach", International Journal of Production Research, 53(11), pp. 3370-3389 (2015). DOI: 10.1080/00207543.2014.986294

26. Keršulienè, V., Zavadskas, E.K., and Turskis, Z. "Selection of rational dispute resolution method by applying new step-wise weight assessment ratio analysis (SWARA)", Journal of Business Economics and Management, 11(2), pp. 243-258 (2010). DOI: $10.3846 /$ jbem. 2010.12

27. Farahmand, M. and Desa, M.I. "RED: a new method for performance ranking of large decision making units", Soft Computing, 21(5), pp. 1271-1290 (2017). DOI: $10.1007 / \mathrm{s} 00500-015-1860-9$

28. Aghaie, A. and Heidary, M.H. "Simulation-based optimization of a stochastic supply chain considering supplier disruption: Agent-based modeling and reinforcement learning", Scientia Iranica, 26 (6), pp. 37803795 (2019). DOI: $10.24200 /$ sci.2018.20789

29. Pergher, I., Frej, E.A., Roselli, L.R.P., et al. "Integrating simulation and FITradeoff method for scheduling rules selection in job-shop production systems", International Journal of Production Economics, 227, 107669 (2020). DOI: 10.1016/j.ijpe.2020.107669

30. Laurindo, Q.M.G., Peixoto, T.A., and Rangel, J.J.A. "Communication mechanism of the discrete event simulation and the mechanical project software for manufacturing systems", Journal of Computational Design and Engineering, 6(1), pp. 70-80 (2019). DOI: 10.1016/j.jcde.2018.02.005

31. Piccinini, A., Previdi, F., Cimini, C., et al. "Discrete event simulation for the reconfiguration of a flexible manufacturing plant", IFAC-Papers OnLine, 51(11), pp. 465-470 (2018). DOI: 10.1016/j.ifacol.2018.08.362

32. Hatami-Marbini, A., Sajadi, S.M., and Malekpour, H. "Optimal control and simulation for production planning of network failure-prone manufacturing systems with perishable goods", Computers and Industrial Engineering, 146, p. 106614 (2020). DOI: 10.1016/j.cie.2020.106614

33. Montgomery, D.C., Design and Analysis of Experiments, Wiley, 9th Edn. (2017).

34. Garg, H. and Kaur, G. "Extended TOPSIS method for multi-criteria group decision-making problems under cubic intuitionistic fuzzy environment", Scientia Iranica, 27(1), pp. 396-410 (2020). DOI: $10.24200 /$ sci. 2018.5307 .1194
35. Alinezhad, A., Sarrafha, K., and Amini, A. "Sensitivity analysis of SAW technique: the impact of changing the decision making matrix elements on the final ranking of alternatives", Iranian Journal of Operations Research, 5(1), pp. 82-94 (2014). DOI: 10.1016/j.ijor.2014.10.132

36. Mousavi-Nasab, S.H. and Sotoudeh-Anvai, A. "A comprehensive MCDM-based approach using TOPSIS, COPRAS and DEA as an auxiliary tool for material selection problems", Materials \& Design, 121, pp. 237-253 (2017). DOI: 10.1016/j.matdes.2017.02.041

37. Alinezhad, A. and Khalili, J., New Methods and Applications in Multiple Attribute Decision Making (MADM), International Series in Operations Research \& Management Science, Springer (2017).

38. Alinezhad, A., Makui, A., and Mavi, R.K.M. "An inverse DEA model for inputs/outputs estimation with respect to decision maker's preferences: The case of Refah bank of IRAN", Mathematical Sciences, 1(1,2), pp. 61-70 (2007).

39. Omrani, H., Keshavarz, M., and Ghaderi, S.F. "Evaluation of supply chain of a shipping company in Iran by a fuzzy relational network data envelopment analysis model", Scientia Iranica, 25(2), pp. 868-890 (2018). DOI: $10.24200 /$ sci. 2017.4415

\section{Biographies}

Nafise Monazzam is a PhD student in Industrial Engineering and Operations Research and Systems Engineering from the Islamic Azad University of Qazvin. Her research areas include simulation, DEA, MCDM, supply chain, and production management.

Alireza Alinezhad is currently an Associate Professor at the Department of Industrial Engineering, Qazvin Branch, Islamic Azad University, Qzvin, Iran. His research areas of interest encompass DEA, MCDM, and quality engineering and management.

Mohammad Amin Adibi is currently an Assistant Professor at the Department of Industrial Engineering, Qazvin Branch, Islamic Azad University, Qazvin, Iran. $\mathrm{He}$ is interested in research areas such as operations research, data mining, quality management, and productivity. 